\title{
CONTEXTUALIZAÇÃO DA ORIENTAÇÃO SEXUAL NO AMBIENTE ESCOLAR
}

\section{Gizely Azevedo Costa ${ }^{1}$ \\ Caroline Tavares Firmino ${ }^{2}$ \\ Priscilla Cortizo Costa Pierro ${ }^{3}$}

Resumo: Desenvolver a temática sexualidade nem sempre é uma tarefa fácil, entretanto nos dias atuais na qual os adolescentes estão inseridos têm se feito uma tarefa de primordial importância, necessitando de uma contextualização coerente e adequada. Diante disso a pesquisa em questão teve por objetivo realizar um levantamento bibliográfico da temática enfatizando a forma como a orientação sexual vem sendo abordada no contexto escolar. Para isso fez-se uso do método de revisão de literatura onde foram selecionados diversos artigos científicos com considerações pertinentes em relação ao assunto. Por meio dos dados encontrados foi possível constatar que a orientação sexual não vem sendo trabalhada em sua forma ampla, desmistificando e trabalhando as questões mais polêmicas e consistentes em relação ao tema, tendo principalmente na maioria das vezes abordagens voltadas para o cunho biológico apenas, fato decorrente da falta de formação adequada para os professores.

Palavras-chave: Adolescência; Contextualização; Orientação sexual; Sexualidade.

\footnotetext{
${ }^{1}$ Bacharelado em Ciências biológicas/Instituto Federal do Espírito Santo - Campus de Alegre, Brasil. E-mail: gizelyac.11@hotmail.com.

2 Bacharelado em Ciências biológicas/ Instituto Federal do Espírito Santo - Campus de Alegre, Brasil. E-mail: carolzinhatavares13@hotmail.com.

${ }^{3}$ Docente Mestre/Instituto Federal do Espírito Santo - Campus de Alegre, Brasil. E-mail: pri.cortizo@gmail.com.
} 